\title{
A Review on Laboratory Findings of Patients with COVID-19 Infection
}

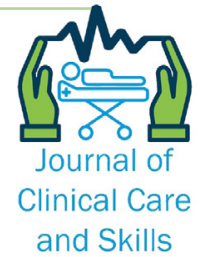

and Skills

\section{ARTICLE INFO}

\section{Article Type}

Systematic Review

\section{Authors}

Daneshyar Z.*1 $M D$,

Rahimi N. ${ }^{1} M S C$

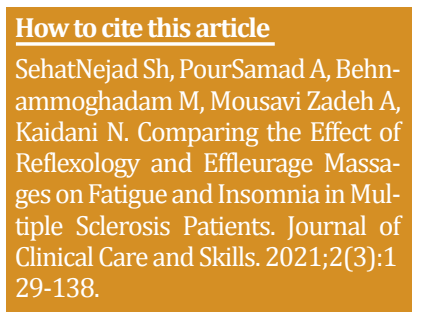

\section{A B S T RA C T}

Aims This study aimed to evaluate the diagnostic and laboratory findings of infections caused by acute coronavirus syndrome 2 (SARS-CoV-2).

Information \& Methods This systematic review was carried out using research in Google Scholar, international databases such as Pubmed, Wiley, and Sciencedirect, and Iranian databases including SID and Magiran by the keywords SARS-CoV-2, COVID-19 diagnostic methods, PCR, COVID-19, and hematology parameters. Finally, 93 articles were selected and reviewed.

Findings Reverse transcription-polymerase chain reaction and molecular test methods are the method of choice to diagnose the cause of SARS-CoV-2 infection. Serological testing is not yet sensitive enough and specific for diagnosis. The clinical spectrum of the infection is wide, including asymptomatic infection, relatively mild upper respiratory tract disease, and severe viral pneumonia with respiratory failure and even death. The incidence of lymphopenia, thrombocytopenia, and coagulation disorders occur in severe cases of the disease and are associated with a poor prognosis. An increase of D-dimer levels in severe cases of the disease suggests anticoagulant therapy. In severe disease, laboratory tests show changes in the immune system with overstimulation of the cytokine storm. In addition, biomarkers of specific organs indicate heart, kidney, and liver dysfunction in many patients.

Conclusion Although virus detection by reverse transcription-polymerase chain reaction is the gold standard, if the test is negative, the definitive diagnosis of COVID-19 should be based on clinical data; other tests for complications of the disease are also important.

Keywords SARS-CoV-2; Polymerase Chain Reaction; Hematology
${ }^{1}$ Clinical Research Development Unit, Imamsajad Hospital, Yasuj University of Medical Sciences, Yasuj, Iran

\section{*Correspondence}

Address: Clinical Research Development Unit, Imamsajad Hospital, Yasuj University of Medical Sciences, Yasuj, Iran. Postal Code: 7183833387.

Phone: +98 (917) 3168417

Fax: -

zahradaneshyar@yums.ac.ir

\section{Article History}

Received: June 07, 2021

Accepted: September 09, 2021

ePublished: September 12, 2021

\section{T A T I O N L I N K S}

[1] Addendum ... [2] ScRNA-seq ... [3] Measuring ... [4] Interspecies ... [5] Molecular ... [6] Temporal ... [7] Review ... [8] What other ... [9] Asymptomatic ... [10] Water ... [11] Presumed ... [12] Epidemiological ... [13] Clinical ... [14] An overview ... [15] Encephalitis ... [16] Neurological ... [17] A novel ... [18] Report ... [19] Laboratory ... [20] Molecular ... [21] Persistence ... [22] Discontinuation ... [23] Interim ... [24] Specimen ... [25] Technical ... [26] Comparison ... [27] A combination ... [28] Comparison ... [29] Quantitative ... [30] Broadly ... [31] Real-time ... [32] A-Z of quantitative ... [33] Research ... [34] CDC 2019-novel ... [35] Multiple ... [36] Detection ... [37] Molecular ... [38] Practical ... [39] Molecular ... [40] Cross-reactive ... [41] Hematologic ... [42] Clinical ... [43] Dysregulation ... [44] The critical ... [45] Clinical ... [46] Clinical ... [47] Risk ... [48] Epidemiologic ... [49] Laboratory ... [50] COVID-19 ... [51] The neutrophil ... [52] Neutrophil ... [53] Leukoerythroblastic ... [54] Dynamic ... [55] High ... [56] IL-19 induces ... [57] Increased ... [58] Simulation ... [59] Thrombocytopenia ... [60] Mechanism ... [61] COVID-19 ... [62] Clinical ... [63] Clinical ... [64] Clinical ... [65] Abnormal ... [66] Coagulation ... [67] Hyperferritinemia ... [68] Clinical ... [69] Clinical ... [70] Potential ... [71] Clinical ... [72] Risk ... [73] Plasma ... [74] A tool ... [75] Hematologic ... [76] Blood ... [77] Physiology ... [78] The association ... [79] Is albumin ... [80] How is ... [81] Usefulness ... [82] Risk ... [83] Suspected ... [84] Kidney ... [85] Liver ... [86] COVID-19 ... [87] Liver ... [88] TH17 responses ... [89] COVID-19 ... [90] Important ... [91] Clinical ... [92] COVID-19 ... [93] Laboratory ... 


\section{Introduction}

In late December 2019, a case of unidentified pneumonia led to an epidemic in Wuhan City, Hubei Province, China. The World Health Organization and the International Committee for Classification of Viruses named the virus COVID-19 and SARS-CoV-2 $[1,2]$. The virus has infected 200 million people worldwide so far. 4 million people have been infected in Iran, and about 100,000 deaths have been reported due to the virus [3]. This is an RNA virus, a member of the coronavirus family, and spreads much faster than MERS-CoV and SARS-CoV [4-6]. COVID-19 is a highly contagious disease that the World Health Organization has declared as a World Health Emergency. Most patients with COVID-19 are adults and middle-aged people, and the highest mortality rate is related to older men with an average age of 75 years, but the virus can also infect young and healthy people. Also, approximately 20\% of COVID-19 patients develop severe respiratory disease which the mortality rate in all cases is about $2.3 \%{ }^{[7-9]}$.

The major modes of transmission of the virus are respiratory droplets and direct contact. Asymptomatic carriers can also transmit and spread the COVID-19 virus [10,11]. Patient analysis in some articles shows the average incubation period of about seven days and in some about four days ${ }^{[12,13]}$. Most patients have mild to moderate symptoms. Asymptomatic patients have also been reported. Therefore, early and accurate diagnosis of SARS-CoV2 infection is essential to prevent and control the epidemic.

Heterogeneity of clinical manifestations, from asymptomatic individuals to severe disease cases and the variety of nonspecific clinical manifestations of COVID-19, reinforces the need for complementary trials with good sensitivity and specificity. The gold standard for detecting and detecting an infectious agent is visualizing viral particles under an electron microscope or tissue culture to study virus replication in vitro. However, these methods require technology available in research centers. Monitoring the patients with COVID-19 has shown that the virus, in addition to respiratory failure and ARDS, can cause symptoms outside the respiratory tracts and expand the range of related clinical manifestations. Other complications include liver damage, acute myocardial injury, acute kidney injury, septic shock, and even multiple organ failure [14]. Neurological complications in patients with COVID-19 infection can also manifest as acute encephalopathy and an altered level of consciousness. In all these cases, more knowledge is needed to diagnose the complications of this new and rapidly expanding virus, which has unknown features in modern medicine. Therefore, identify biomarkers that can predict the disease's type, severity, and prognosis $[15,16]$.
This study aimed to evaluate the diagnostic and laboratory findings of infections caused by acute respiratory syndrome due to SARS-CoV-2.

\section{Information and Methods}

This systematic review was carried out using research in Google Scholar, international databases such as Pubmed, Wiley, and Science Direct, and Iranian databases including SID and Magiran by the keywords SARS-CoV-2, COVID-19 diagnostic methods, PCR COVID-19, and hematology parameters. Out of 120 articles, 93 articles [1-93] were selected and reviewed.

\section{Findings \\ Laboratory diagnostic methods to diagnose the cause of COVID-19}

Causal tests may be direct (such as culture or reverse transcription-polymerase chain reaction (RT-PCR) to detect the virus itself) or indirect (to determine the humoral immune response to SARS-CoV-2).

\section{Culture}

Isolation and culture of the virus are performed on human respiratory tract epithelial cells, Vero E6 cells, or Huh-7 cells. It took about 96 hours for SARS-CoV2 to be cultured in human respiratory tract epithelial cells, and its cultivation in Vero E6 or Huh-7 cells took about six days. Virus isolation and culture should be performed on surface biosafety (BSL-3). Laboratory personnel should wear protective equipment, including disposable gloves, gowns or coveralls, scrub clothes, or a one-piece suit covering the arms, head, and shoe cover. The use of the cultivation method is not recommended due to the high cost and time-consuming routine.

\section{Nucleic acids}

Nucleic acid testing is the main method of diagnosing COVID-19, and sample collecting is the most important step in laboratory diagnosis. A sample that is not collected correctly will lead to incorrect test results. For initial diagnostic testing for SARS-CoV-2 infections, the US Centers for Disease Control and Prevention recommends the upper respiratory specimen. First, it is recommended to use synthetic fiber swabs with a plastic shaft and a sterile container for sample collecting. Calcium alginate swabs or a wooden shaft should not be used because they may contain inactivate viruses and inhibit PCR testing. Second, swabs must be placed correctly to obtain sufficient virus-infected cells. In detail, the nasopharyngeal swab (NP) should be inserted parallel to the palate through a flexible swab, and the oropharyngeal swab (OP) should be wiped in the posterior pharyngeal wall and tonsils. The combined samples of NP and OP can increase the susceptibility to respiratory viruses. Samples should be refrigerated and sent to the laboratory immediately. 


\section{1}

Nucleic acid sequencing (NAAT) should be performed at a Biosafety Level 2 laboratory (BSL-2). RT-PCR involves the reverse transcription of 2SARS-CoVviral RNA into complementary DNA (cDNA), then amplifies some cDNA areas. One of the advantages of the RT-PCR method is that it allows the analysis of gene expression of very small amounts of RNA even at the content level of a single cell. In addition, this method can be performed on several specimens or different genes in an experiment.

The RT-PCR method can be performed in one or two steps. In the one-step method, where the entire reaction from cDNA synthesis to PCR amplification is performed in a single tube, reverse transcription and PCR amplification are integrated into one reaction, and reverse transcription occurs during testing. This type of method provides fast and reproducible results for analysis with high acceptance capacity. The challenge with this method is using an RNA start pattern as the template, which will be prone to rapid degradation if not properly controlled. In addition, one-step protocols are less sensitive than two-step protocols.

Nevertheless, in the two-step method, the reactions are performed sequentially in separate tubes. This method is more sensitive than the one-step method but requires more time and optimization of additional parameters. It is also more likely to increase DNA contamination in this method.

US Centers for Disease Control and Prevention uses RT-PCR (RRT-PCR), a one-step procedure, which provides numerical data on viral volume to detect the presence of SARS-CoV-2. In China, the National Bureau of Medical Production has authorized the company to use the PMseq and DNBSEQ-T7 metagenomics sequencing kit for emergency use. It helps to control the epidemic by identifying patients with COVID-19 and dynamically detecting recurrent mutations in the virus.

The researchers examined several viral gene sequences to differentiate 2019-nCoV from SARS$\mathrm{CoV}$ to design a set of primers and probes. Among SARS-dependent genes, they identified three regions with conserved sequences: E gene (protein gene) and RdRP gene (RNA-dependent RNA-polymerase gene), which were highly sensitive to detection. In contrast, the $\mathrm{N}$ gene (nucleocapsid protein gene) showed less sensitivity in each reaction. Therefore, a system can be designed to diagnose different coronaviruses, including SARS-CoV-2 publicly, and the second primer is determined exclusively to identify SARSCoV-2. Also, the one-step RT-PCR method was designed using primers for $\mathrm{N}$ and $\mathrm{ORF}-1 \mathrm{~b}$ genes. Therefore, it can be used for disease screening, and ORFlb gene primers can be used as a confirmatory test.

The problem with the RT-PCR method is the lack of access to PCR kits. Regardless of the method, the sensitivity and specificity of different RT-PCR kits are
Daneshyar Z. \& Rahimi N.

not $100 \%$. Although this method is the gold standard for diagnosing SARS-CoV-2 infection, its sensitivity and specificity are estimated at $70 \%$ and $95 \%$, respectively. Sample collection method and disease severity are effective in test results. So that, the test results for people with mild symptoms and low virus load are falsely negative. If the asymptomatic patient is recovered from SARS-CoV-2 PCR, the PCR test will not detect this previous infection, so monitoring measures will not be applied.

\section{Serological testing}

Virus protein antigens and antibodies produced in response to SARS-CoV-2 infection may contribute to COVID-19 disease. The virus enters the human body through SPIKE (protein S) enters the target cells in the upper respiratory tract by binding to the angiotensin-converting enzyme-2. Antibodies against $\mathrm{S}$ protein are very specific for SARS-CoV-2; their surface is well correlated with the virus neutralization capacity. However, there is a needs to explain the role of antibodies compared to other proteins in the pathogenesis of COVID-19, even promoting further virus penetration into cells. Antibodies produced in response to viral proteins may provide a wider time window for the indirect diagnosis of SARS-CoV-2. In addition, other factors that interfere with the results are included the duration of symptoms during blood collecting and the severity of the clinical picture. Viral volume in posterior pharynx specimens from patients with COVID-19 was compared with two types of RBD and IgP antibodies in the patient's serum; the positive rates were $94-100 \%$ for IgG, $94 \%$ for antibodies, and 88-94\% for IgM. Also, immunoglobulin G and M (IgG and IgM) were evaluated in the serum of COVID-19 patients treated for ten days using the ELISA method. The results showed that both IgM and IgG were relatively low or undetectable during the initial sampling on the first day. However, an increase in viral antibodies is seen in almost all patients during the fifth day. IgM appears to increase significantly since the fifth day and from the eighth day. IgG also increased from the tenth day of onset of symptoms and after the 14th day. Therefore, these tests are not suitable for the early diagnosis of COVID-19. It has recently been shown that IgG levels decrease significantly after two or three months. The role of these antibodies in protecting a person from reinfection is still unknown. Studies have shown that serological testing can improve the diagnosis rate; however, it is difficult to determine the true sensitivity values and characteristics for these experiments. One of the potential challenges in designing accurate serological tests involves the possible cross-reactivity of SARS-CoV-2 antibodies with the antibodies produced against other coronaviruses.

\section{Supportive trials}

Some tests show COVID-19-related complications or 
risk factors for complications.

\section{Hematology findings}

Hematology laboratory parameters are not usually used to diagnose COVID-19 due to their low sensitivity and specificity. However, they are valuable prognosis indices and provide useful information about the severity of the disease, the duration of the disease, and the response to treatment.

Changes in white blood cell count and relationship with pathogenicity

The results showed that $36 \%$ of patients had lymphopenia at the time of admission. Reexamination of peripheral blood in the hospital showed that most patients (69\%) were lymphopenic and people who needed an ICU had reduced lymphocytes. A study conducted by several scientists on 1,099 patients with positive COVID-19 was hospitalized in 550 hospitals in China (33.7\%) showed that patients had leukopenia at admission time, and this indicator was more in severe cases of the disease. People with severe disease had higher leukocyte, and neutrophil counts, decreased lymphocytes, and increased neutrophil-tolymphocyte ratio. In one study, leukocytosis was identified as one of the most important prognostic parameters for severe COVID-19 disease. In particular, the study of patients suggested an association between lymphopenia and leukocytosis and neutrophilia and the need for intensive care units (ICU).

There was no consistent difference between the WBC categories in children, and the leukocyte count was normal in $69 \%$ of cases. In a few children, an increase or decrease in leukocytes was observed, which did not affect the prognosis of patients compared to adult patients. However, in a study of 9 Iranian children with COVID-19, aged 2-10, Leukopenia and lymphopenia were observed in 3 children. The disease had a good prognosis in children, and they were all discharged during six days through supportive care. Lymphopenia, leukocytosis, and neutrophilia appear to be associated with more severe disease and worse prognosis in adults, but it has no cause side effects in children.

\section{Neutrophils}

Neutrophil-lymphocyte ratio (NLR) is simply the number of neutrophils divided by the number of lymphocytes And is valid in showing the general state of inflammation in the patient. People with severe disease have a lower lymphocyte count, leukocyte count, and neutrophil-lymphocyte ratio than nonseverely patients. Also, there is an $8 \%$ higher risk of in-hospital mortality for every unit increase in NLR. According to the findings, the inflammatory response can stimulate the production of neutrophils and accelerate lymphocytes apoptosis. The inflammatory response can stimulate neutrophil production and accelerate lymphocytes apoptosis. Abnormalities in immunological responses and poor regulated immune responses play an important role in exacerbating viral diseases. When the immune response is out of control, it can lead to severe inflammation and even death. A 46-year-old woman on peripheral blood smear showed leukoerythroblastic reaction with normocytic anemia and mild dacrocytes; neutrophilia and immature myeloid cells such as myelocytes and promyelocytes were significant, which during the improvement of clinical condition, neutrophilia resolved and other blood findings slowly improved. Lymphocytes in peripheral blood, including T cells, B cells, and natural killer (NK) cells, are involved in humoral and cellular immunity against viral infections. The effective immune response to viral infection depends on the activation of cytotoxic CD8+cells, which destroy the virus-infected cells. Also, regulatory $\mathrm{T}$ cells play an important role in preventing excessive and harmful immune reactions to pathogens. Therefore, a better understanding of the cellular immunoreactivity in COVID-19 could provide new insights into the pathogenesis of the disease. In the early stages of the disease (days 1 to 14), leukocytes and lymphocytes count in the peripheral blood is normal or slightly reduced. Sarscov-2 often affects tissues expressing high levels of the angiotensin-converting enzyme, including the heart, lungs, and digestive system. 7 to 14 days after early symptoms, an increase in inflammatory mediators and cytokines characterized by a cytokine storm occurs. Significant lymphopenia (involving both $\mathrm{T}$ and $\mathrm{B}$ cell lines) is seen at this time, and inflammatory factors increase in the peripheral blood. Oral mucosal lymphocytes, like gastrointestinal lymphocytes and lungs, express angiotensin, two receptors on their surface. Therefore, it can be concluded that SARS-CoV-2 can directly infect these cells and lead to their lysis. In addition, cytokine storms can accelerate lymphocyte apoptosis (IL-6, IL-7, GCSF, MCPI, MIP1- $\alpha$, TNF- $\alpha$ ) by significantly increasing interleukin levels. Significant activation of cytokines can also be associated with atrophy of lymphoid organs such as the spleen and further disrupt the circulation of lymphocytes.

\section{Thrombocytopenia}

Based on studies, platelet counting seems to be a rapid, accessible, cost-effective, and simple laboratory parameter, which can distinguish between patients with severe and non-severe diseases and is independently related to the severity of the disease and the risk of death in the ICU. In addition, the findings showed that platelet depletion was associated with a threefold increased risk of disease. Thrombocytopenia is a condition in which the platelet count drops to less than 150,000 per microliter of blood and usually indicates a physiological lack of compensation without an underlying hematological defect. The mechanism of thrombocytopenia is usually multifactorial in COVID19 patients. Several mechanisms have been proposed for thrombocytopenia in SARS: A) SARS can directly 
infect hematopoietic cells and bone marrow stromal cells, causing apoptosis and inhibition of cell growth; B) This virus can cause damage to blood cells by the immune cell through inducing the production of immune complexes and autoantibodies; $\mathrm{C}$ ) The virus induces a weak degree of DIC, which is disrupted by clotting time and an increase in D-dimer; DIC consumes platelets and reduces their number; D) The virus can reduce the production or increase the consumption of platelets in damaged lungs. Further studies on the mechanism of thrombocytopenia can provide valuable theoretical resources for timely clinical treatment and a more comprehensive understanding of the disease.

\section{Coagulation disorder tests}

Side effects of viral infection in patients in the severe phase of the disease cause activation of several systemic inflammatory and coagulation responses, which are vital for the host defense system but can lead to DIC. Stimulation of host inflammatory responses also leads to increased production of proinflammatory cytokines. This event leads to the activation of the coagulation cascade and consumable coagulopathy, which is common among COVID-19 patients, especially those with severe forms. The primary coagulation disorders are associated with increasing D-dimer FDP, whereas abnormalities in prothrombin time (PT), partial thromboplastin time (PTT), and platelet count in the early stages are relatively unusual. Therefore, for screening coagulation tests, measurement of D-dimer and fibrinogen levels is recommended. It was found that the risk of death in hospital was associated with a Ddimer greater than $1 \mu \mathrm{g} / \mathrm{ml}$ upon admission. COVID19 appears to be able to activate the coagulation cascade through various mechanisms, leading to severe hypercoagulability. Early anticoagulant therapy can stop clot formation and reduce micro thrombosis, thereby reducing the risk of major organ damage. In a study on 183 patients (including 162 Survivors and 21 non-survivors), according to the diagnostic criteria of the International Association of Thrombosis and Homeostasis, the deceased had significantly longer D-dimer, FDP, PT, and PTT upon admission than the survivors, and $71.4 \%$ of the patients who died in the hospital had DIC and the average time between admission to the hospital and the onset of DIC was about four days. Patients with viral infection may develop sepsis. Sepsis is one of the major causes of DIC. DIC occurs when monocytes and endothelial cells are activated following injury and secrete cytokines, tissue factor, and von Willebrand factor. Free thrombin circulation, uncontrolled by natural anticoagulants, can activate platelets and stimulate fibrinolysis. In the late stages of COVID-19, levels of fibrin-related markers (D-dimer and FDP) increase in all cases leading to death, indicating activation of coagulation cascade or secondary hyperfibrinolysis in these patients. The combination of thrombocytopenia, prolonged PT, and increased D-
Daneshyar Z. \& Rahimi N.

dimer indicates DIC; however, this pattern is markedly different from the DIC in sepsis.

In sepsis, thrombocytopenia is usually very prominent, and D-dimer in sepsis is lower than in COVID-19 patients. Indeed, many COVID-19 patients cannot be considered to have DIC according to criteria from the International Association of Thrombosis and Homeostasis. Therefore, coagulopathy associated with COVID-19 appears to be a combination of low-grade DIC and localized pulmonary thrombotic microangiopathy, which can significantly affect organ dysfunction in patients with severe forms of the disease. Increased fibrinogen and D-dimer are common in patients with COVID-19 due to coagulation dysfunction. In a study conducted in Shanghai to investigate the relationship between coagulopathy with COVID-19, patients with COVID19 were divided into two groups of relatively mild $(n=277)$ and severe disease $(n=26)$; the average of coagulation parameters in the severe disease group was higher than the relatively mild disease group; International Normalized Ratio (INR): 1.04 compared to 1.01 , PT: 13.8 vs. 13.4 seconds, APTT: 43.2 vs. 39.2 seconds, Fibrinogen: 4.74 vs. $4.33 \mathrm{~g} / \mathrm{l}$, FDP: 2.61 vs. $0.99 \mu \mathrm{g} / \mathrm{ml}, \mathrm{D}$-dimer: $1.04 \mathrm{vs.} 0.43 \mu \mathrm{g} / \mathrm{ml}$. According to the results, DIC is more common in deaths with COVID-19, and abnormal coagulation tests especially increased D-dimer and FDP, can guide the treatment process and prognosis evaluation.

\section{Common inflammatory markers of acute-phase reactors}

The regulation of ferritin synthesis is controlled by cytokines. Therefore, the intense immune activity in the field of cytokine storms observed in critical and fatal cases of COVID-19 leads to the regulation of serum ferritin levels. Indeed, initial data of the patients suggest that excessive ferritin levels are seen in COVID-19 patients, from $400 \mu \mathrm{g} / \mathrm{l}$ to more than $2000 \mu \mathrm{g} / \mathrm{l}$, with the highest trend in cases with severe disease non-surviving people. It has been reported that the rate of erythrocyte sedimentation rate (ESR) of people in critical condition is higher than those who have recovered (median ESR 38.5 vs. $28 \mathrm{~mm} / \mathrm{h}$ ). Also, ESR was recognized as the strongest factor for predicting disease progression and diagnosing severe COVID-19 patients in the early stages of COVID-19.

There is a similar trend for C-reactive protein (CRP) compared to ESR, except that in the deceased, the CRP quadrupled (median concentration 113 vs. $26.2 \mathrm{~m} / \mathrm{l})$. There is a significant increase in the frequency of higher CRP concentrations between severe and critical disease cases compared with moderate disease. The researcher reported that higher CRP levels were inversely associated with disease progression. Researchers measured CRP as a prognostic factor for COVID-19 at the time of admission, and it was found that higher plasma CRP levels indicate severe pneumonia in COVID-19 and longer hospitalization. The results of other studies 
also show that the concentration of procalcitonin is higher in severe disease than in moderate. These results indicate an increase in the level of systemic inflammation in severe diseases. However, some studies have found lower PCT changes compared to other laboratory parameters. Albumin is a negatively acute phase reactant with antioxidant properties whose synthesis is regulated by inflammatory cytokines. Therefore, it is not surprising that hypoalbuminemia (usually less than $30 \mathrm{~g} / \mathrm{L}$ ) is persistent in patients with severe or fatal COVID-19. In addition, a study showed that low albumin concentrations were associated with a failure recovery of the disease. Hypoalbuminemia has also been reported as a risk factor among other parameters for predicting the risk of severe COVID19. Serum amyloid A (SAA) is another acute-phase reactant that prevents monocyte motility, platelet activation, fever, and various chemotherapy routes. Nevertheless, high concentrations of SAA among all patients with COVID-19 have been reported in only one study (there is no significant difference between severe and non-severe cases).

\section{Cardiac biomarkers}

Cardiac troponin I and $\mathrm{T}$ are highly sensitive and specific biomarkers of myocardial damage, which can be caused by myocardial ischemia, inflammation, immune response, and toxins. Results of troponin evaluation of 6247 patients over 48 hours showed 4426 patients with normal troponin (71\%), 919 patients with slightly increased troponin (15\%), and 902 patients with severely increased troponin (14\%). In patients with high troponin, the risk of death was significantly higher than normal troponin, and this risk is independent of the underlying cardiovascular disease. In another study, an increased troponin was observed in more than half of the no survival patients upon admission. Regardless of the underlying cardiovascular disease, patients with a dynamic increase in troponin during hospitalization were likely to have fatal outcomes. The main mechanism of troponin increase in patients with COVID-19 is unknown. Myocardial damage in COVID-19 patients may be associated with systemic inflammation rather than a viral attack. Directly, increased levels of CK-MB and NT-proBNP can also be seen in patients with severe COVID-19 compared to non-severe patients.

\section{Kidney tests}

In a group study on 701 patients with COVID-19, the ratios of proteinuria, hematuria, and abnormal serum creatinine and urea nitrogen at admission were 43.9, $26.7,14.4$, and $13.1 \%$, respectively. In addition, there was a high prevalence (5.1\%) of acute kidney injury (AKI) during the study period. Proteinuria, hematuria, and elevated serum creatinine/nitrogen urea on admission and AKI were independent risk factors for death during hospitalization, and patients with kidney disease have a significantly higher risk of death in the hospital. Autopsy of 26 COVID-19 patients showed significant histopathology of acute kidney damage, and it was found that tubular epithelial cells were directly infected with SARSCoV2. Therefore, SARS-CoV2 may cause kidney injury or exacerbate kidney disease. Therefore, monitoring renal function and AKI occurrence in patients with COVID-19 should not be neglected.

\section{Liver function tests}

Abnormal liver function tests, like increasing ALT, AST, TBIL, and GGT, and decreased albumin levels are relatively common in patients with COVID-19, and there is abnormal ALT or AST in $10-33 \%$ of these patients. However, patients with severe COVID-19 appear to have severe liver dysfunction. However, the levels of ALT, AST, TBIL, and GGT in COVID-19 patients were not significantly different from those in pneumonia patients. The mean level of transaminase in severe COVID-19 patients is less than twice as high as the reference level, and liver damage in COVID-19 is not clinically significant.

Elevated aminotransferase is not necessarily due to liver injury, and COVID-19 infection may cause myositis inflammation similar to severe influenza infections or liver dysfunction related to liver injury due to inflammation, hepatotoxicity, and hypoxia due to medication.

\section{Biochemical markers and arterial blood gases}

Lactate dehydrogenase (LDH) is a cytoplasmic enzyme present in any tissue, and its high realizing indicates major organ damage. Therefore, LDH is expected to increase in severe cases of COVID-19, where multiple organ damage occurs. Current data indicate that LDH levels are significantly higher in fatal diseases (usually more than 320U/L). In addition, higher LDH quadruples the risk of disease failure. Finally, higher LDH concentrations at admission are associated with a higher risk of COVID19 and therefore added to the initial prognosis tool for severe infection. Other findings also show that an increase or decrease in LDH is associated with radiographic enhancement or improvement. LDH normalization time is positively correlated with radiographic recovery time. The use of increased LDH has a good feature to predict disease progression.

Examination of lipid is essential in the SARS-CoV-2 infection. The clinical significance of plasma lipid profiles during COVID-19 disease has not been accurately assessed. In a cross-sectional observational study on 1411 hospitalized patients with COVID-19, total cholesterol, LDL cholesterol, and HDL serum cholesterol were analyzed to predict the prognosis of COVID-19 (severe disease vs. mild disease); patients with severe COVID-19 disease had lower HDL cholesterol and higher triglycerides before infection. The lipid profile measured during hospitalization also showed a relationship between the severe disease with lower HDL cholesterol and higher triglyceride levels.

Secondary hemophagocytic lymphocytocytosis (sHLH) is an over-inflammatory syndrome associated with fatal hypercytokinemia and multiple 
organ failure in adults. SHLH is usually caused by viral infections, and sepsis occurs in 3.7-4.3\% of cases. The main features of sHLH include persistent fever, cytopenias, hyperferritinemia, and pulmonary involvement (including ARDS) that occur in 50\% of patients and is present in COVID 19 and is associated with disease severity. Cytokine profiles in COVID-19 include increased IL-2 and IL-7, granulocyte colonystimulating factor, interferon-gamma, TNF-alpha, which these cytokines are predictors of death, which may be due to excessive inflammation caused by the virus. In one study, more than $50 \%$ of patients who died had a relative arterial oxygen pressure (PaO2) less than $60 \mathrm{~mm} \mathrm{Hg}$. CT score correlates with arterial blood gas indices; therefore, arterial blood gases are an important prognostic tool for disease severity because they are directly related to lung function impairment.

\section{Discussion}

The gold standard for diagnosing SARS-CoV-2 infection is the diagnosis by viral genetic material by RT-PCR, in various specimens, with higher sensitivity in the nasopharyngeal swab. Many factors related to the individual, the specimen collecting method, and the testing technique interfere with the sensitivity of the tests. Therefore, a negative test in a patient with a clear clinical picture should not rule out the possibility of COVID-19. In addition, due to virus mutations and the emergence of species with different characteristics, the sensitivity of existing tests may be reduced. For this purpose, there must be dynamism in the study of the virus genome. Existing serological tests are different, and many factors affect their sensitivity and specificity. There is no detectable antibody level in all patients with SARSCoV-2 infection, especially if they have milder symptoms. Lack of antibodies does not mean any contact or no protection against the virus. Also, the presence of antibodies does not rule out the possibility of infection; however, better detection and recognition of antibodies with high sensitivity and specificity will play an effective role in reducing costs and increasing the speed and ease of testing.

In the case of additional tests, hematology tests help determine the prognosis of the disease. According to the articles, lymphopenia, leukocytosis, neutrophilia, increased neutrophil-lymphocyte ratio, and thrombocytopenia is present in some patients with COVID-19. They are associated with more severity and a worse prognosis in adults but do not cause many side effects in children. Research has shown that the side effects of this virus in pregnant women are not more than normal people [94]; however, the virus is constantly mutating, and new species may need to be re-examined. Also, due to the spread of the virus in Iran, more specific studies should be performed on pregnant women or infants, who are more exposed to the disease by new variants [95].
Daneshyar Z. \& Rahimi N.

The index of other auxiliary tests rises according to the injured organs. High levels of CRP, ferritin, Ddimer, procalcitonin, $\mathrm{LDH}$, prothrombin time, partial thromboplastin activation time, serum amyloid A protein, creatine kinase, urea, and creatinine are risk factors for more severe diseases, And liver and liver tests are usually less affected by the disease. It is better to do more specific research on testing people with immunodeficiency. Cytokine profile tests in COVID-19, including increased IL-2, IL-7, granulocyte colony-stimulating factor, interferon-gamma, TNFalpha, are predictors of death, which are not routinely available in Iran due to their high cost. Due to the regulation of ferritin synthesis by cytokines, increasing ferritin levels can be substituted for check factors such as interleukin and TNF-alpha [67].

Serological tests can improve the positive rate of diagnosis. However, it is difficult to determine the sensitivity values and characteristics for serological tests. The clinical spectrum of infection varies, including asymptomatic infection, relatively mild illness, or eventually severe viral pneumonia with respiratory failure and even death. The incidence of lymphopenia, thrombocytopenia, and coagulation disorders are induced in severe cases of the disease and are associated with a poor prognosis. Elevated Dimer-D levels in severe cases suggest anticoagulant therapy. Early anticoagulant therapy can stop clot formation and reduce micro thrombosis, thereby reducing the risk of major organ damage. In severe cases, laboratory tests show changes in the immune system with overstimulation of the cytokine storm. In addition, biomarkers of specific organs indicate involvement of heart muscle, kidney, and liver dysfunction in many patients.

In this study, we tried to provide useful and brief information about the new coronavirus by addressing the findings and laboratory methods for the diagnosis. An accurate and comprehensive evaluation of laboratory parameters at all clinical stages of the disease can help physicians diagnose early and provide more care for people at higher risk.

\section{Conclusion}

Although virus diagnosis by reverse transcriptionpolymerase chain reaction is the gold standard, if the test is negative, the definitive diagnosis of COVID-19 should be based on clinical data; other tests for complications of the disease are also important.

Acknowledgments: No cases have been mentioned by the authors.

Ethical Permissions: The ethical principles have been observed in this study, and the article has been reviewed by the ethics committee of Yasouj University of Medical Sciences.

Conflicts of Interests: There was no conflict of interest. Authors' Contribution: Daneshyar Z. (First Author), Introduction Writer/Discussion Writer (70\%); Rahimi N. 
(Second Author), Introduction Writer/Discussion Writer (30\%).

Funding/Support: This study has not been funded.

\section{References}

1- Zhou P, Yang X-L, Wang X-G, Hu B, Zhang L, Zhang W, et al. Addendum: A pneumonia outbreak associated with a new coronavirus of probable bat origin. Nature. 2020;588(7836):6.

2- Wang Z, Xu X. ScRNA-seq profiling of human testes reveals the presence of the ACE2 receptor, a target for SARS-CoV-2 infection in spermatogonia, leydig and sertoli cells. Cells. 2020;9(4):920.

3- Clarke JM, Majeed A, Beaney T. Measuring the impact of COVID-19. BMJ. 2021;373:1239.

4- Chan JFW, To KKW, Tse H, Jin DY, Yuen KY. Interspecies transmission and emergence of novel viruses: Lessons from bats and birds. Trends Microbiol. 2013;21(10):544-55.

5- He J, Tao H, Yan Y, Huang SY, Xiao Y. Molecular mechanism of evolution and human infection with SARSCoV-2. Viruses. 2020;12(4):428.

6- To KK, Tsang OT, Leung WS, Tam AR, Wu TC, Lung DC, et al. Temporal profiles of viral load in posterior oropharyngeal saliva samples and serum antibody responses during infection by SARS-CoV-2: An observational cohort study. Lancet Infect Dis. 2020;20(5):565-74.

7- Wang L, Wang Y, Ye D, Liu Q. Review of the 2019 novel coronavirus (SARS-CoV-2) 297 based on current evidence. Int J Antimicrob Agents. 2020;55(6):105948.

8- Boccia S, Ricciardi W, Ioannidis JPA. What other countries can learn from italy during the COVID-19 pandemic. JAMA Intern Med. 2020;180(7):927-8.

9- Lai CC, Liu YH, Wang CY, Wang YH, Hsueh SC, Yen MY, et al. Asymptomatic carrier state, acute respiratory disease, and pneumonia due to severe acute respiratory syndrome coronavirus 2 (SARS-CoV-2): Facts and myths. J Microbiol Immunol Infect. 2020;53(3):404-12.

10- Worl health organization. Water, sanitation, hygiene, and waste management for the COVID-19 virus: Interim guidance [Internet]. Geneva: World Health Organization; 2020 [cited 2020 April 23]. Available from:

11- Bai Y, Yao L, Wei T, Tian F, Jin DY, Chen L, et al. Presumed asymptomatic carrier transmission of COVID-19. JAMA. 2020;323(14):1406-7.

12- Wang $\mathrm{P}, \mathrm{Lu} J$, Jin $\mathrm{Y}, \mathrm{Zhu} \mathrm{M}$, Wang $\mathrm{L}$, Chen $\mathrm{S}$. Epidemiological characteristics of 1212 COVID-19 patients in Henan, China. MedRxiv. 2020 Feb:1-11.

13- Xu XW, Wu XX, Jiang XG, Xu KJ, Ying LJ, Ma CL, et al. Clinical findings in a group of patients infected with the 2019 novel coronavirus (SARS-Cov-2) outside of Wuhan, China: Retrospective case series. BMJ. 2020;368:606.

14- Shi Y, Wang G, Cai XP, Deng JW, Zheng L, Zhu HH, et al. An overview of COVID-19. J Zhejiang Univ Sci B. 2020;21(5):343-60.

15- Ye M, Ren Y, Lv T. Encephalitis as a clinical manifestation of COVID-19. Brain Behav Immun. 2020;88:945-6.

16- Filatov A, Sharma P, Hindi F, Espinosa PS. Neurological complications of coronavirus disease (COVID-19): Encephalopathy. Cureus. 2020;12(3):7352.

17- Zhu N, Zhang D, Wang W, Li X, Yang B, Song J, et al. A novel coronavirus from patients with pneumonia in China, 2019. N Engl J Med. 2020;382(8):727-33.

18- World health organization. Report of the WHO-China joint mission on coronavirus disease 2019 (COVID-19)
[Internet]. Geneva: World Health Organization; 2020 [cited: Unknown]. Available from: https://www.who.int/publications/i/item/report-of-thewho-china-joint-mission-on-coronavirus-disease-2019(covid-19).

19- World health organization. Laboratory biosafety guidance related to coronavirus disease 2019 (COVID-19): Interim guidance [Internet]. Geneva: World Health Organization; 2020 [cited 2020 Feb 12]. Available from: https://www.who.int/publications/i/item/WHO-WPEGIH-2021.1.

20- Zhang W, Du RH, Li B, Zheng XS, Yang XL, Hu B, et al. Molecular and serological investigation of 2019-nCoV infected patients: Implication of multiple shedding routes. Emerg Microbes Infect. 2020;9(1):386-9.

21- Ling Y, Xu SB, Lin YX, Tian D, Zhu ZQ, Dai FH, et al. Persistence and clearance of viral RNA in 2019 novel coronavirus disease rehabilitation patients. Chinese Med J. 2020;133(9):1039-43.

22- Centers for disease control and preventation. Discontinuation of transmission-based precautions and disposition of patients with SARS-CoV-2 infection in healthcare settings [Internet]. Atlanta: Centers for Disease Control and Preventation; 2021 [cited: Unknown]. Available from: https://www.cdc.gov/coronavirus/2019ncov/hcp/disposition-hospitalized-patients.html.

23- Centers for disease control and preventation. Interim guidelines for collecting and handling of clinical specimens for COVID-19 testing [Internet]. Atlanta: Centers for Disease Control and Preventation; 2021[cited: Unknown]. Available from: https://www.cdc.gov/coronavirus/2019ncov/lab/guidelines-clinical-specimens.html.

24- Centers for disease control and preventation. Specimen collection guidelines [Internet]. Atlanta: Centers for Disease Control and Preventation; 2021 [cited: Unknown]. Available from: Not Found.

25- China CDC weekly. Technical guidelines for COVID-19 laboratory testing [Internet]. Beijing: China CDC Weekly; 2020 [cited: Unknown]. Available from: http://weekly.chinacdc.cn/en/article/id/0f6dc581-08f44828-97f0-9cc805969bbb.

26- Kim C, Ahmed JA, Eidex RB, Nyoka R, Waiboci LW, Erdman D, et al. Comparison of nasopharyngeal and oropharyngeal swabs for the diagnosis of eight respiratory viruses by real-time reverse transcription-PCR assays. Plos One. 2011;6(6):21610.

27- Ek P, Bottiger B, Dahlman D, Hansen KB, Nyman M, Nilsson AC. A combination of naso-and oropharyngeal swabs improves the diagnostic yield of respiratory viruses in adult emergency department patients. Infect Dis. 2019;51(4):241-8.

28- Spencer S, Thompson MG, Flannery B, Fry A. Comparison of respiratory specimen collection methods for detection of influenza virus infection by reverse transcription-PCR: A literature review. J Clin Microbiol. 2019;57(9):19-27.

29- Freeman WM, Walker SJ, Vrana KE. Quantitative RTPCR: Pitfalls and potential. Biotechniques. 1999;26(1):11222.

30- Kageyama T, Kojima S, Shinohara M, Uchida K, Fukushi $\mathrm{S}$, Hoshino FB, et al. Broadly reactive and highly sensitive assay for Norwalk-like viruses based on real-time quantitative reverse transcription-PCR. J Clin Microbiol. 2003;41(4):1548-57.

31- Wong ML, Medrano JF. Real-time PCR for mRNA quantitation. Biotechniques. 2005;39(1):75-85. 
32- Bustin SA. A-Z of quantitative PCR. La Jolla: International University Line; 2004.

33- Centers for disease control and preventation. Research use only 2019-novel coronavirus (2019-nCoV) real-time RT-PCR primers and probes [Internet]. Atlanta: Centers for Disease Control and Prevention; 2020 [cited: Unknown]. Available from: https://www.cdc.gov/coronavirus/2019ncov/lab/rt-pcr-panel-primer-probes.html.

34- FDA. CDC 2019-novel coronavirus (2019-nCoV) realtime RT-PCR diagnostic panel [Internet]. Silver Spring: FDA; 2020 [cited: Unknown]. Available from: https://www.fda.gov/media/134922/.

35- American accociation for clinical chemistry. Multiple coronavirus tests receive regulatory approvals worldwide [Internet]. Washington: American Accociation for Clinical Chemistry; 2020 [cited: Unknown]. https://www.aacc.org/cln/articles/2020/april/multiplecoronavirus-tests-receive-regulatory-approvals-

worldwide.

36- Corman VM, Landt O, Kaiser M, Molenkamp R, Meijer A, Chu DK, et al. Detection of 2019 novel coronaviruse (2019nCoV) by real-time RT-PCR. Eur Surveill. 2020;25(3):2000045.

37- Chu DKW, Pan Y, Cheng SMS, Hui KPY, Krishnan P, Liu $\mathrm{Y}$, et al. Molecular diagnosis of a novel coronavirus (2019nCoV) causing an outbreak of pneumonia. Clin Chem. 2020;66(4):549-55.

38- Shariff M, Soon S, Lee KL, Tan LT. Practical problems with PCR detection in Asia: The importance of standardization [Internet]. FAO; 2000 [Cited: Unknown]. Available

from:

http://www.fao.org/3/X4946E/x4946e0d.htm.

39- Li X, Geng M, Peng Y, Meng L, Lu S. Molecular immune pathogenesis and diagnosis of COVID-19. J Pharm Anal. 2020;10(2):102-8.

40- Lv H, Wu NC, Tsang OTY, Yuan M, Perera RA, Leung WS, et al. Cross-reactive antibody response between SARS-CoV2 and SARS-CoV infections. Cell Rep. 2020;31(9):107725.

41- Fan BE. Hematologic parameters in patients with COVID-19 infection: A reply. Am J Hematol. 2020;95(8):215.

42- Guan WJ, Ni ZY, Hu Y, Liang WH, Ou CQ, He JX, et al. Clinical characteristics of coronavirus disease 2019 in China. N Engl J Med. 2020;382:1708-20.

43- Qin C, Zhou L, Hu Z, Zhang S, Yang S, Tao Y, et al. Dysregulation of immune response in patients with coronavirus 2019 (COVID-19) in Wuhan, China. Clin Infect Dis. 2020;71(15):762-8.

44- Lippi G, Plebani M. The critical role of laboratory medicine during coronavirus disease 2019 (COVID-19) and other viral outbreaks. Clin Chem Lab Med. 2020;58(7):1063-9.

45- Huang C, Wang Y, Li X, Ren L, Zhao J, Hu Y, et al. Clinical features of patients infected with 2019 novel coronavirus in Wuhan, China. Lancet. 2020;395(10223):497-506.

46- Wang D, Hu B, Hu C, Zhu F, Liu X, Zhang J, et al. Clinical characteristics of 138 hospitalized patients with 2019 novel coronavirus-infected pneumonia in Wuhan, China. JAMA. 2020;323(11):1061-9.

47- Wu C, Chen X, Cai Y, Zhou X, Xu S, Huang H, et al. Risk factors associated with acute respiratory distress syndrome and death in patients with coronavirus disease 2019 pneumonia in Wuhan, China. JAMA Intern Med. 2020;180(7):934-43.

48- Young BE, Ong SWX, Kalimuddin S, Low JG, Tan SY, Loh J, et al. Epidemiologic features and clinical course of
Daneshyar Z. \& Rahimi N.

patients infected with SARS-CoV-2 in Singapore. JAMA. 2020;323(15):1488-94.

49- Henry BM, Lippi G, Plebani M. Laboratory abnormalities in children with novel coronavirus disease 2019. Clin Chem Lab Med. 2020;58(7):1135-8.

50- Rahimzadeh G, Ekrami Noghabi M, Kadkhodaei Elyaderani F, Navaeifar MR, Enayati AA, Manafi Anari A, et al. COVID-19 infection in Iranian children: A case series of 9 patients. J Pediatr Rev. 2020;8(1):139-44.

51- Faria SS, Fernandes Jr PC, Silva MJB, Lima VC, Fontes W, Freitas-Junior R, et al. The neutrophil-to-lymphocyte ratio: A narrative review. Ecancermedicalscience. 2016;10:702. 52- Liu Y, Du X, Chen J, Jin Y, Peng L, Wang HH, et al. Neutrophil-to-lymphocyte ratio as an independent risk factor for mortality in hospitalized patients with COVID-19. J Infect. 2020;81(1):6-12.

53- Mitra A, Dwyre DM, Schivo M, Thompson III GR, Cohen $\mathrm{SH}, \mathrm{Ku} \mathrm{N}$, et al. Leukoerythroblastic reaction in a patient with COVID-19 infection. Am J Hematol. 202095(8):9991000.

54- Rezaei M, Marjani M, Mahmoudi S, Mortaz E, Mansouri D. Dynamic changes of lymphocyte subsets in the course of covid-19. Int Arch Allergy Immunol. 2021;182(3):254-62. 55- Singh S, Sharma A, Arora SK. High producer haplotype (CAG) of -863C/A, -308G/A and -238G/A polymorphisms in the promoter region of TNF- $\alpha$ gene associate with enhanced apoptosis of lymphocytes in HIV-1 subtype C infected individuals from north India. Plos One. 2014;9(5):98020.

56- Liao YC, Liang WG, Chen FW, Hsu JH, Yang JJ, Chang MS. IL-19 induces production of IL- 6 and TNF- $\alpha$ and results in cell apoptosis through TNF- $\alpha$. J Immunol. 2002;169(8):4288-97.

57- Aggarwal S, Gollapudi S, Gupta S. Increased TNF- $\alpha-$ induced apoptosis in lymphocytes from aged humans: Changes in TNF- $\alpha$ receptor expression and activation of caspases. J Immunol. 1999;162(4):2154-61.

58- Chan JFW, Zhang AJ, Yuan S, Poon VKM, Chan CCS, Lee $A C Y$, et al. Simulation of the clinical and pathological manifestations of coronavirus disease 2019 (COVID-19) in a golden Syrian hamster model: Implications for disease pathogenesis and transmissibility. Clin Infect Dis. 2020;71(9):2428-46.

59- Lippi G, Plebani M, Henry BM. Thrombocytopenia is associated with severe coronavirus disease 2019 (COVID19) infections: A meta-analysis. Clin Chim Acta. 2020;506:145-8.

60- Xu P, Zhou Q, Xu J. Mechanism of thrombocytopenia in COVID-19 patients. Ann Hematol. 2020;99(6):1205-8.

61- Connors JM, Levy JH. COVID-19 and its implications for thrombosis and anticoagulation. Blood. 2020;135(23):2033-40.

62- Deng Y, Liu W, Liu K, Fang YY, Shang J, Zhou L, et al. Clinical characteristics of fatal and recovered cases of coronavirus disease 2019 in Wuhan, China: A retrospective study. Chinese Med J. 2020;133(11):1261-7.

63- Zhou F, Yu T, Du R, Fan G, Liu Y, Liu Z, et al. Clinical course and risk factors for mortality of adult inpatients with COVID-19 in Wuhan, China: A retrospective cohort study. Lancet. 2020;395(10229):1054-62.

64- $\mathrm{Li} \mathrm{T}$, Lu H, Zhang W. Clinical observation and management of COVID-19 patients. Emerg Microbes Infect. 2020;9(1):687-90.

65- Tang N, Li D, Wang X, Sun Z. Abnormal coagulation parameters are associated with poor prognosis in patients with novel coronavirus pneumonia. J Thromb Haemost. 


\section{0;18(4):844-7.}

66- Levi M, Thachil J, Iba T, Levy JH. Coagulation abnormalities and thrombosis in patients with COVID-19. Lancet Haematol. 2020;7(6):438-40.

67- Kernan KF, Carcillo JA. Hyperferritinemia and inflammation. Int Immunol. 2017;29(9):401-9.

68- Chen T, Wu D, Chen H, Yan W, Yang D, Chen G, et al. Clinical characteristics of 113 deceased patients with coronavirus disease 2019: Retrospective study. BMJ. 2020;368:1295.

69- Chen G, Wu D, Guo W, Cao Y, Huang D, Wang H, et al. Clinical and immunological features of severe and moderate coronavirus disease 2019. J Clin Invest. 2020;130(5):2620-9.

70- Zhang H, Wang X, Fu Z, Luo M, Zhang Z, Zhang K, et al. Potential factors for prediction of disease severity of COVID-19 patients. MedRxiv. 2020 Mar:1-26.

71- Zhang JJ, Dong X, Cao YY, Yuan YD, Yang YB, Yan YQ, et al. Clinical characteristics of 140 patients infected with SARS-CoV-2 in Wuhan, China. Allergy. 2020;75(7):1730-41. 72- Zhang J, Wang X, Jia X, Li J, Hu K, Chen G, et al. Risk factors for disease severity, unimprovement, and mortality in COVID-19 patients in Wuhan, Chin. Clin Microbiol Infect. 2020;26(6):767-72.

73- Chen W, Zheng KI, Liu S, Yan Z, Xu C, Qiao Z. Plasma CRP level is positively associated with the severity of COVID-19. Ann Clin Microbiol Antimicrob. 2020;19(1):18.

74- Gong J, Ou J, Qiu X, Jie Y, Chen Y, Yuan L, et al. A tool for early prediction of severe coronavirus disease 2019 (COVID-19): A multicenter study using the risk nomogram in Wuhan and Guangdong, China. Clin Infect Dis. 2020;71(15):833-40.

75- Henry BM, De Oliveira MHS, Benoit S, Plebani M, Lippi G. Hematologic, biochemical and immune biomarker abnormalities associated with severe illness and mortality in coronavirus disease 2019 (COVID-19): A meta-analysis. Clin Chem Lab Med. 2020;58(7):1021-8.

76- Thomas J, Pociute A, Kevalas R, Malinauskas M, Jankauskaite L. Blood biomarkers differentiating viral versus bacterial pneumonia aetiology: A literature review. Ital J Pediatr. 2020;46(1):4.

77- Gulhar R, Ashraf MA, Jialal I. Physiology, acute phase reactants. StatPearls; 2018.

78- Aziz M, Fatima R, Lee-Smith W, Assaly R. The association of low serum albumin level with severe COVID19: A systematic review and meta-analysis. Crit Care. 2020;24(1):255.

79- Violi F, Cangemi R, Romiti GF, Ceccarelli G, Oliva A, Alessandri $\mathrm{F}$, et al. Is albumin predictor of mortality in COVID-19. Antioxid Redox Signal. 2021;35(2):139-42.

80- Mair J, Lindahl B, Hammarsten O, Muller C, Giannitsis E, Huber $\mathrm{K}$, et al. How is cardiac troponin released from injured myocardium. Eur Heart J Acute Cardiovasc Care. 2018;7(6):553-60.

81- Majure DT, Gruberg L, Saba SG, Kvasnovsky C, Hirsch JS, Jauhar R, et al. Usefulness of elevated troponin to predict death in patients with COVID-19 and myocardial injury. Am J Cardiol. 2021;138:100-6.

82- Li X, Xu S, Yu M, Wang K, Tao Y, Zhou Y, et al. Risk factors for severity and mortality in adult COVID-19 inpatients in Wuhan. J Allergy Clin Immunol. 2020;146(1):110-8.

83- Deng Q, Hu B, Zhang Y, Wang H, Zhou X, Hu W, et al. Suspected myocardial injury in patients with COVID-19: evidence from front-line clinical observation in Wuhan, China. Int J Cardiol. 2020;311:116-21.

84- Cheng Y, Luo R, Wang K, Zhang M, Wang Z, Dong L, et al. Kidney disease is associated with in-hospital death of patients with COVID-19. Kidney Int. 2020;97(5):829-38.

85- Zhang Y, Zheng L, Liu L, Zhao M, Xiao J, Zhao Q. Liver impairment in COVID-19 patients: A retrospective analysis of 115 cases from a single centre in Wuhan city, China. Liver Int. 2020;40(9):2095-103.

86- Bangash MN, Patel J, Parekh D. COVID-19 and the liver: little cause for concern. Lancet Gastroenterol Hepatol. 2020;5(6):529-30.

87- Zhang C, Shi L, Wang FS. Liver injury in COVID-19: management and challenges. Lancet Gastroenterol Hepatol. 2020;5(5):428-30.

88- Wu D, Yang XO. TH17 responses in cytokine storm of COVID-19: An emerging target of JAK2 inhibitor fedratinib. J Microbiol Immunol Infect. 2020;53(3):368-70.

89- Mehta P, McAuley DF, Brown M, Sanchez E, Tattersall RS, Manson JJ. COVID-19: Consider cytokine storm syndromes and immunosuppression. Lancet. 2020;395(10229):1033-4.

90- European society of intensive care medicine. Important announcement of new SSC guidelines-COVID-19 [Internet]. Unknown Publisher City. European Society of Intensive Care Medicine; 2020 [cited: Unknown]. Available from: https://www.esicm.org/ssc-covid19-guidelines/.

91- Shang Y, Xu C, Jiang F, Huang R, Li Y, Zhou Y, et al. Clinical characteristics and changes of chest CT features in 307 patients with common COVID-19 pneumonia infected SARS-CoV-2: A multicenter study in Jiangsu, China. Int J Infect Dis. 2020;96:157-62.

92- Kasraeian M, Zare M, Vafaei H, Asadi N, Faraji A, Bazrafshan K, et al. COVID-19 pneumonia and pregnancy: A systematic review and meta-analysis. J Matern Fetal Neonatal Med. 2020 May:1-8.

93- Vakili S, Savardashtaki A, Jamalnia S, Tabrizi R, Nematollahi MH, Jafarinia M, et al. Laboratory findings of COVID-19 infection are conflicting in different age groups and pregnant women: A literature review. Arch Med Res. 2020;51(7):603-7. 